\title{
O FUNCIONAMENTO DAS NOÇÓES DE "LÍNGUA FLUIDA” E “LÍNGUA IMAGINÁRIA”: O CASO DE UMA GRAMÁTICA NORMATIVA
}

\section{THE FUNCTIONING OF THE CONCEPTS OF “ FLOWED LANGUAGE AND “IMAGINARY LANGUAGE”: THE CASE OF A NORMATIVE GRAMMAR}

\author{
Marcia Ione Surdi \\ Universidade Comunitária da Região de Chapecó, Chapecó, SC, Brasil \\ Universidade Federal de Santa Maria, Programa de Pós-Graduação em Letras, \\ Santa Maria, RS, Brasil \\ Mary Neiva Surdi da Luz \\ Universidade Federal da Fronteira Sul, Chapecó, SC, Brasil
}

\begin{abstract}
Resumo: Neste artigo, analisamos o funcionamento das noçóes de língua fluida e língua imaginária, no texto introdutório da Gramática Normativa da Língua Portuguesa (1972), de Carlos Henrique da Rocha Lima. Partindo da ideia de que estamos tratando de efeitos de evidência produzidos na e pela língua é que se tornou pertinente lançar um olhar, sob o enfoque da Análise de Discurso, de linha francesa, para se compreender o modo como o sujeito gramático concebe e como se dá o funcionamento da relação língua fluida/língua imaginária no objeto de análise, assim como esses elementos marcam as tomadas de posição sujeito, sustentadoras do dizer do gramático, em sua relação com a língua.
\end{abstract}

Palavras-chave: língua fluida; língua imaginária; gramática normativa; discurso.

Abstract: In this article, we analyze the functioning of the notions of fluid language and imaginary language in the introductory text of Gramática Normativa da Língua Portuguesa (1972), by Carlos Henrique da Rocha Lima. Starting from the idea that we are dealing with effects of evidence, produced in and by the language, it became relevant to cast a glance, from the perspective of Discourse Analysis of French line, to understand how the grammatical subject conceives them and how the relationship between fluid language/imaginary language works in the object of analysis, as well as these elements define the taking of subject positions that support the grammarian's saying in his relationship with the language.

Keywords: flowed language; imaginary language; normative grammar; discourse.

\section{Um lugar para se dizer}

As análises que propomos neste artigo advêm das reflexốes que vêm sendo realizadas em trabalho de doutoramento e que se constituem 
em continuidade à pesquisa de mestrado ${ }^{1}$ desenvolvida por Surdi (2010). Conta-se também com a colaboração de Surdi da Luz (2010) que, a partir dos estudos de diferentes instrumentos linguísticos, especialmente os de circulação em situação de ensino de língua, propóe-se a refletir sobre o funcionamento da noção de língua em diferentes materialidades.

\section{Sobre a noçáo de língua}

Tomando como base a perspectiva discursivista, concebemos a língua no mundo como as maneiras de significar e náo enquanto sistema fechado. Levamos em conta o homem na história, considerando as condiçóes de produção da linguagem e a concepçáo de que a mesma não é transparente, como afirma Eni Orlandi, em sua produção bibliográfica em Análise do Discurso (SURDI, 2010).

Michel Pêcheux, fundador da Análise de Discurso francesa (AD), como leitor e estudioso de vários linguistas, dentre eles Saussure, Chomsky e Benveniste, retoma e ressignifica alguns conceitos fundamentais para a Teoria do Discurso que propóe (PETRI, 2006). O autor reconhece que o corte epistemológico proposto por Saussure foi necessário para marcar a fundação da Linguística como ciência, mas não aceita a dicotomia língua/ fala, em que o segundo termo é excluído, justamente por ver que está na fala, como manifestaçáo intersubjetiva, a potencialidade dos estudos da linguagem e que língua e discurso são constitutivos.

Segundo Maldidier (2003), o discurso produzido por Pêcheux não invoca a superação da dicotomia língua/fala, pois, para ele, Saussure é o ponto de origem da ciência linguística e o deslocamento proposto da função para o funcionamento da língua é "um adquirido científico irreversível" (MALDIDIER, 2003, p. 22).

Para Gadet e Pêcheux (2004, p. 55), "Saussure constitui, direta ou indiretamente, a pedra de toque de todas as linguísticas atuais, o seu ponto de partida crítico".

De acordo como Paveau e Sarfati (2006), Saussure definiu a língua como o objeto da Linguística e fundou a Linguística moderna, operando uma "ruptura com a linguística comparatista de sua época, propondo uma abordagem não histórica, descritiva e sistemática (dir-se-á, mais tarde, 'estrutural')" (PAVEAU e SARFATI, 2006, p. 63). O estruturalismo foi

\footnotetext{
${ }^{1}$ Gramática Normativa: movimentos e funcionamentos do "diferente" no "mesmo", sob orientação da Profa. Dr. Verli Petri.
} 
marcado por um retorno aos trabalhos de Saussure, em especial ao Curso de Linguística Geral (1916).

Em Pêcheux (1999), encontramos também a ideia de que Saussure pôs-se a pensar contra seu tempo, rompendo com uma série de interrogaçôes pré-linguísticas sobre a origem da linguagem e suas determinaçóes biológicas, lógicas, sócio-históricas ou filosóficas. Também afirma Pêcheux que "o estado atual da Linguística é que o ponto inaugural permanece evanescente, e que a ruptura por ele suposta nunca é efetuada" (PÊCHEUX, 1999, p. 9, grifos do autor).

Desse modo, observa-se que Pêcheux, para constituir a Teoria do Discurso, dá um atributo às teorias que precederam sua produção, não nega o constructo teórico que já se constituíra no campo das ciências da linguagem, mas, a partir do que já está posto, propóe o novo, um deslocamento a partir do que já existe: o novo no interior do "mesmo".

Nas palavras de Petri (2006, p. 09),

É Pêcheux quem nos convida a pensar sobre a necessidade de abertura das questôes da linguagem, caminhando em direção à discursividade, pois para ele já estava muito claro que é no discurso que podemos perceber o lugar onde a história trabalha, fazendo a diferença, pois ela comporta o contraditório, o conflitante, o instável.

Nesse mesmo sentido, em que se supera a noção de homogeneidade e simetria, Ferreira (2003) afirma que a língua do analista de discurso é a língua da ordem material, da opacidade, da possibilidade do equívoco como fato estruturante, da marca da historicidade inscrita na língua, da indefinição do direito e avesso, do dentro e fora, da presença e ausência. Nesse sentido, é preciso dizer que a noção de equívoco que se adota na perspectiva discursivista não corresponde à ideia de "erro", não é um engano: é algo constitutivo: "O equívoco na língua é estruturante para o discurso, é ele que permite que haja entrecruzamento de posiçôes discursivas, condicionando deste modo o funcionamento ideológico" (HORTA NUNES, 2006, p. 31).

A língua, sob o olhar dos discursivistas, não é um sistema perfeito, nem uma unidade fechada, a língua, sim, é sujeita a falhas e é afetada pela incompletude. Logo, falha e incompletude não são defeitos, são antes qualidades da língua em sua materialidade. Não queremos estabelecer uma relação meramente opositiva e direta entre qualidade e defeito, pois, se fosse assim, teríamos interesse somente pelos "defeitos" da língua, sobre o que vem sendo taxado de "erro", mas quando nos entrelaçamos à teoria do discurso, 
nossas leituras coadunam com a perspectiva da diferença, da mudança, do equívoco serem o lugar do possível na língua (ORLANDI, 2009).

É nesse sentido que a $\mathrm{AD}$ nos traz outros (seus) modos de pensar e de definir a língua, ou línguas. Línguas, porque a língua se movimenta e funciona, e é por esse movimento e funcionamento que se pode perceber a presença de uma língua limitada, regrada, fechada, pura e dita perfeita, e a presença de outra língua "ilimitada, desregrada, aberta, profana e imperfeita”. Nas palavras de Orlandi (2009), estamos tratando de língua imaginária e língua fluida, uma relação tensa e contraditória.

\section{Língua fluida e língua imaginária}

No Brasil, é através do processo de historicização da língua portuguesa que se percebem as diferenças na língua. Orlandi (2005a) explica que essas diferenças são produzidas pela relação do português brasileiro com as línguas africanas, indígenas e dos imigrantes. A língua brasileira tem suas variantes que se constituem no continente americano e em relação ao espaço em que se pratica: a deste território habitado por diferentes línguas: "o Brasil tem sua língua oficial, ao lado das muitas línguas indígenas, falares regionais, línguas de imigração etc." (ORLANDI, 2007b, p. 59).

Essas definições fazem emergir o que Orlandi e Souza (1988) nomeiam de língua fluida e língua imaginária. A história da primeira é feita de fartura e movimento e nela convivem processos muito diferentes; portanto, a língua fluida é a que não pode ser contida no arcabouço dos sistemas e fórmulas. É a língua do uso, do coloquial, do "errado" e da oralidade. Segundo as autoras:

\footnotetext{
A língua fluida é a que pode ser observada e reconhecida quando focalizamos os processos discursivos, através da história da constituição de formas e sentidos, tomando os textos como unidade (significativas) de produção. (ORLANDI; SOUZA, 1988, p. 34)
}

Por sua vez, a língua imaginária é a que os estudiosos fixam na sua sistematização, é a língua da norma, do padráo, do correto e da escrita. Línguas imaginárias "são as línguas-sistemas, normas, coerções, as línguasinstituiçôes, a-históricas. É a sistematização que faz com que elas percam a fluidez e se fixem em línguas imaginárias" (ORLANDI; SOUZA, 1988, p. 28). 
Na obra Língua e conhecimento linguístico, Orlandi (2002) trata de língua fluida (língua do mundo, sem regras que a aprisiona, língua no acontecimento do significar na relação de homens com homens, sujeitos e sujeitos) e de língua imaginária (língua do sistema fechado, normas, artefato do linguista e de outros), como modos distintos de existência da linguagem, retomando para tanto Pêcheux e Gadet (2004), no que diz respeito à distinção metodológica do fato de que existe língua e existem línguas, nas palavras dos autores, a língua gramatical e o corpo pleno da língua.

Em Guimarães (2003) encontramos reflexôes acerca da noção de língua fluida, aquela que trata das relaçôes cotidianas, abarca duas categorias de língua. Uma é a língua materna: "língua cujos falantes a praticam pelo fato de a sociedade em que nasce a praticar; e a outra é a língua franca: é praticada por grupos de falantes de línguas maternas diferentes, e que são falantes desta língua para o intercurso comum" (GUIMARÁES, 2003, p. 48). Quanto à língua imaginária, vinculada às relaçôes imaginárias (ideológicas) e institucionais, o autor expóe que ela também abarca duas categorias de língua: a língua nacional e a língua oficial. A primeira "é a língua de um povo, enquanto língua que o caracteriza, que dá a seus falantes uma relação de pertencimento a este povo" (GUIMARÃES, 2003, p. 48). A segunda é a língua de um Estado, aquela que é obrigatória nas açóes formais do Estado, nos seus atos legais. A explicitação que o autor apresenta ajuda-nos a compreender o funcionamento da noção de língua quando estamos tratando de um instrumento linguístico/normativo que representa o Estado/Nação e revela o que há de oficial. A língua padráo é que propóe apresentar, via Gramática Normativa da Língua Portuguesa (GNLP), o modo de escrever e falar um bom Português.

Em um texto intitulado Lingua Brasileira, Orlandi (2005b) faz uma distinção entre língua fluida e língua imaginária, estabelecendo que a primeira é o brasileiro; já a segunda é o português. Oscila-se entre uma língua outorgada, legado de Portugal, intocável, e uma língua nossa, que falamos em nosso dia a dia, a língua brasileira. A tensão provocada por esse movimento não para de produzir sentidos. Os ecos dessa relação, colonizador e colonizado, continuam produzindo sentidos na elaboraçáo de instrumentos linguísticos.

Pautando-nos nas citaçóes anteriores, buscamos as primeiras reflexóes de Orlandi sobre língua fluida e língua imaginária, explicitando o lugar onde há espaço para o "diferente" (SURDI, 2010). Em 2009, Orlandi publica uma obra, intitulada Língua Brasileira e outras histórias, na qual retoma e presentifica suas reflexôes sobre língua fluida e língua imaginária, o que 
vem a acrescentar mais elementos que caracterizam essas línguas. A língua fluida irrompe com qualquer característica da língua imaginária, justamente por ser aquela que encontramos nos processos discursivos, afetada pela ideologia e pelo inconsciente, atravessada pela história, constituída de sentidos e relacionada às condiçóes de produção dos sujeitos. Já para a língua imaginária, a autora estabelece uma relação direta com a noçâo de língua gramatical, aquela que é sistematizada, regrada, formulada, produzida por estudiosos ao longo de sua história e que impregnam o imaginário dos sujeitos na sua relação com a língua. Assim, a língua gramatical caracterizase por perder a fluidez e devido a essa perda fixa-se em língua imaginária.

As incursōes realizadas até o momento fazem-nos compreender que há um percurso, apreensível pelo analista, que pode ser explicitado da seguinte forma:

Quadro 1: Língua



Fonte: Das autoras.

Tais explicitaçôes nos conduzem a refletir as relações entre o "mesmo" e o "diferente" no interior da língua. Gostaríamos de acrescentar à reflexão desses autores o que se projeta na relação entre língua, gramática e sujeito gramático, empreendendo uma breve análise do Quadro 1.

Compreendemos que há língua e línguas; a língua imaginária é da ordem do "mesmo", da regra, da norma, do "bom exemplo". A gramática remete ao lugar de manutenção da língua padrão, numa tentativa de 
interditar a língua fluida e conter os possíveis sentidos que possam emergir. Já a língua fluida esgueira-se por pequenas "frestas", movimenta-se e "só" (e somente se for para isso!) funciona na GNLP para servir de "mau-exemplo". Emerge o "diferente" em um espaço que era da contenção dos sentidos, ao colocar o certo e o errado em relaçáo de oposição franca e aberta, o sujeito crê estar contendo os sentidos. E a parafraseagem parece trabalhar para que isso se realize (SURDI, 2010).

O movimento se dá numa única direção: a preservação da normatividade. Observa-se isso quando se tem a tentativa de apagamento da língua fluida em detrimento da língua imaginária, pois, mesmo que se tenha uma relação contraditória, a língua precisa de uma estrutura, ou seja, de uma gramática.

\section{O funcionamento de língua fluida e língua imaginária no interior da gramática}

A partir das discussões apresentadas, passamos à materialidade linguístico-discursiva: a Introduçẫo da GNLP. Ao longo do texto introdutório, vão sendo elencadas definiçóes de língua que materializam o imaginário presente na tomada de posição-sujeito gramático sobre a língua e revelam os lugares de onde esse sujeito fala. As definiçóes foram recortadas do texto de Introdução da $15^{a}$ edição (1972).

Agora, interessa-nos verificar como se dá o funcionamento das noçôes de língua fluida e língua imaginária no texto introdutório de nosso objeto de análise.

Em uma perspectiva que póe em pauta a relação língua fluida e língua imaginária, podemos apresentar aqui uma sequência discursiva que dá voz e vez a essas noçóes:

Sd 1: Do equilibrio de duas tendências resulta sua estabilidade pelos tempos fora: de um lado, a diferenciação, força natural, espontânea, desagregadora; de outro, a unificação, força coercitiva, disciplinante, conservadora.

No discurso, percebemos como funcionam as noçóes de língua fluida e língua imaginária. É na diferenciação, força natural, espontânea, desagregadora que entra em funcionamento a noção de língua fluida, ou 
seja, a língua cuja história é feita de fartura e movimento, na qual convivem processos diferentes e que náo pode ser contida no arcabouço dos sistemas e fórmulas (SURDI, 2010). Nesse sentido, considerando Orlandi e Souza (1988), podemos construir a seguinte rede de sentidos para representar essa língua fluida:

Quadro 2: Rede de sentidos - língua fluida

\begin{tabular}{|c|}
\hline Diferenciação $=$ língua onde convivem processos diferentes \\
\hline Força natural = língua cuja história é feita de fartura e movimento \\
\hline Desagregadora $=$ língua que não se mobiliza no arcabouço dos sistemas e fórmulas \\
\hline Espontânea $=$ língua do uso, do coloquial, do "errado" e da oralidade \\
\hline
\end{tabular}

Fonte: Das autoras.

De outro lado, localizamos a língua da unificação, força coercitiva, disciplinante, conservadora, portanto, a língua imaginária. Segundo Orlandi e Souza (1988), é o processo de sistematização que faz com que a língua perca a fluidez e se fixe em língua imaginária, ele coloca paradigmas e controla o uso e a forma da língua, além de não permitir que se observe qualquer fato da língua, de qualquer maneira ou perspectiva. Assim, considerando as autoras, podemos construir a seguinte rede de sentidos para representar essa língua imaginária:

Quadro 3: Rede de sentidos - língua imaginária

\begin{tabular}{|c|}
\hline Unificação $=$ língua do sistema/norma \\
\hline Força coercitiva $=$ língua de coerções \\
\hline Disciplinante $=$ língua do correto/padrão \\
\hline Conservadora $=$ língua da escrita, patrimônio \\
\hline
\end{tabular}

Fonte: Das autoras.

Através dos gestos de análise, depreendemos que a concepção de língua revela a tomada de posição do sujeito gramático que marca sua filiação/ identificação à teoria linguística vinculada ao estruturalismo saussureano. Portanto, a perspectiva teórica estruturalista, no que tange à concepçáo de língua, parece ter servido de base para elaboraçáo de gramáticas que 
contemporaneamente temos ao nosso dispor, nesse caso, a de Rocha Lima, que também sofre essa influência. Dito isso, o que podemos ressaltar é que a elaboração da GNLP é marcada por suas condiçôes de produção e nessas histórias emergem as marcas de uma memória discursiva ressignificada, que vem de outros tempos e espaços, bem como pelo trajeto de leitura de quem trabalha nela (SURDI, 2010).

Para entendermos isso, recorremos à desestabilização de evidências $d a$, na e pela língua, voltando nosso olhar para a década de 50, período de elaboração da primeira edição da GNLP, nosso objeto de análise, período esse marcado pela imposição de uma língua imaginária:

[...] a dita língua nacional, da qual um dos documentos de assente e legitimação, além dos dicionários, são as gramáticas publicadas entre as décadas de 30 a 50 e que têm seu parâmetros estipulados a partir dos Programas de Ensino propostos nos textos que regulamentam o ensino (RASIA, 2004, p. 257).

Mesmo com a imposição de uma regulamentação, conforme Surdi (2010), há lugares no discurso do gramático que revelam suas filiaçôes e posiçôes teóricas, assim como há lugares em que deslizam vestígios próprios à língua fluida. Escapa sempre, mesmo quando acreditamos tê-la imobilizado.

Disso rompe o seguinte questionamento: o que faz a língua fluida em um lugar que não é seu? Referimo-nos aqui à GNLP, marcada pela norma, pela regra, pela fixidez e impossibilidade da heterogeneidade linguística ser-lhe constitutiva. Ora, arriscamo-nos a dizer que a língua fluida vem representar o "erro", o incorreto, que existe em oposição ao certo, aquilo que não é imobilizado no sistema, mesmo o heterogêneo sendo constitutivo da língua. A língua fluida é indelével, incontornável, impossível de ser negligenciada. Tem a força da água de um grande rio, podendo ser represada, mas está sempre lá, prestes a arrebentar as comportas e invadir espaços.

Orlandi (2002) assim define a heterogeneidade linguística: "consideramos, pois, a heterogeneidade linguística no sentido de que joga em 'nossa' língua um fundo falso, em que o 'mesmo' abriga, no entanto, um 'outro', um 'diferente' histórico que o constitui ainda que na aparência do 'mesmo'" (ORLANDI, 2002, p. 23). A nossa língua significa em uma filiaçẫo de memória heterogênea.

À moda de Saussure e partindo das noçôes de língua imaginária e língua fluida, propomos as dicotomias, retiradas da $\mathbf{S d} \mathbf{1}$ que identificam essas noçốes: 
Quadro 4: Língua fluida e língua imaginária

\begin{tabular}{|c:c|}
\hline Língua fluida & Língua imaginária \\
\hline Diferenciação & unificação \\
\hline força natural & força coercitiva \\
\hline Espontânea & disciplinante \\
\hline Desagregadora & conservadora \\
\hline
\end{tabular}

Fonte: Das autoras.

Os termos listados na primeira coluna remetem-nos à noçáo de errado/ incorreto; já os termos listados na segunda coluna remetem-nos à noção de correto/certo. Desse modo, podemos observar que os termos listados nas colunas formam redes parafrásticas em que os sentidos imbricam-se e complementam-se. A definição de língua fluida como "língua do mundo, sem regras que a aprisiona, língua no acontecimento do significar na relação de homens com homens" forma uma rede parafrástica com outras definiçôes como: diferenciaçáo, força natural, espontânea e desagregadora. Enquanto a definição de língua imaginária como "língua do sistema fechado, normas, artefato do linguista e de outros" forma uma rede parafrástica com outras definiçốes como: unificação, força coercitiva, disciplinante e conservadora. Formam-se, assim, redes de sentidos, em que o sujeito gramático marca a sua identificação (SURDI, 2010).

No entanto, apesar de propormos esse gesto de leitura em que visualizamos o funcionamento aparentemente dicotômico nas redes parafrásticas, representamos uma linha divisória com traços pontilhados uma vez que compreendemos ser necessário não se tomar as noçôes de língua fluida e língua imaginária como noçôes em oposição, sendo pois inviável delimitarem-se fronteiras conceituais rígida. Entendemos que o sujeito gramático lança-se no esforço de preservação da língua, pois o imaginário e o fluido (co) existem e (co)ocorrem no funcionamento da língua.

\section{No amâgo das relaçóes}

Enfim, por partirmos da ideia de que estamos tratando de efeitos de evidência produzidos na e pela língua é que se tornou pertinente lançar um olhar, sob o enfoque da $\mathrm{AD}$, para se compreender o modo como o gramático 
Rocha Lima concebe e como se dá o funcionamento da relação língua fluida/língua imaginária no objeto de análise, assim como esses elementos marcam as tomadas de posição sujeito, sustentadoras do dizer do gramático, em sua relaçáo com a língua. É interessante como ele faz questão de jogar para fora, é um movimento dos sentidos sempre na mesma direção: o que


sai! Essa é a ordem implícita na gramática, mas de difícil realização. No entanto, o que fica e o que sai são constitutivos da língua. A (co)existência da língua imaginária e da língua fluida é condição sine qua non para o sujeitogramático produzir seu instrumento linguístico. Ou seja, por que escrever uma gramática se não houvesse regras ou usos linguísticos em (co)existência?

Assim, inspiramo-nos no mestre genebrino, quando ele nos ensina que:

Fundamentalmente, a língua repousa sobre diferenças. Menosprezar esse fato, obstinar-se atrás de quantidades positivas é, eu acredito, se condenar a continuar, de uma ponta à outra do estudo linguístico, ao largo do fato verdadeiro, e do fato decisivo em todas as diversas ordens em que somos desafiados a considerar a língua. (SAUSSURE, 2002, p. 66).

Concomitantemente, retomamos o expresso em Orlandi (2009), tratando de língua imaginária e de língua fluida, quando refletimos sobre essa relação tensa e contraditória. A isso, podemos ainda acrescentar: de fronteiras tênues, em que não se pode precisar onde começaria uma ou outra, cabendo entâo ao sujeito-gramático uma tomada de posição em que se tem uma tentativa de delimitação de fronteiras, mas que sempre escapa ao equívoco.

\section{Referências}

FERREIRA, M. C. L. O quadro atual da Análise de Discurso no Brasil. Letras, Programa de Pós-Graduaçáo em Letras, Santa Maria, n. 27, jul./ dez. 2003.

GADET, F.; PÊCHEUX, M. A língua inatingível: o discurso na história da lingüística. Campinas: Pontes, 2004.

GUIMARÁES, E. Enunciação e política de línguas no Brasil. Letras, Programa de Pós-Graduação em Letras, Santa Maria, n. 27, jul./dez. 2003. 
HORTA NUNES, J. Dicionários no Brasil: análise e história do século XVI ao XIX. Campinas: Pontes Editores; São Paulo: Fapesp; São José do Rio Preto: Faperp, 2006.

MALDIDIER, D. A inquietaçáo do discurso - (Re)ler Michel Pêcheux Hoje. Campinas: Pontes, 2003.

ORLANDI, E. P. Língua e conhecimento lingüístico. São Paulo: Cortez, 2002.

. O contato entre línguas e a relação ao outro: uma leitura possível de Serafim da Silva Neto. In: GUIMARÁES, E.; BRUM-DE-PAULA, M. R. (Org.). Sentido e memória. Campinas: Pontes, 2005 a.

Alíngua brasileira. Ciência e Cultura, São Paulo, vol. 57, n. 2, jun. 2005b. Disponível em: <http://cienciaecultura.bvs.br/scielo.php?script=sci_ arttext\&pid=S0009 67252005000200016\&lng=en\&nrm=iso $>$. Acesso em: 06 jan. 2014.

Língua brasileira e outras histórias: discurso sobre a língua e ensino no Brasil. Campinas: Editora RG, 2009.

ORLANDI, E. P.; SOUZA, T. C. C. A língua imaginária e a língua fluida: dois métodos de trabalho com a linguagem. In: ORLANDI, E. P. Política lingüística na América Latina. Campinas: Pontes, 1988.

PAVEAU, M-A; SARFATI, G-E. As grandes Teorias da Lingüística: da Gramática Comparada à Pragmática. Tradução Rosário Gregolin et al. São Carlos: Claraluz, 2006.

PÊCHEUX, M. Sobre a desconstrução das teorias lingüísticas. Línguas e Instrumentos Lingüísticos, n. 2. Campinas: Pontes, 1999, 7-32.

PETRI, V. Michel Pêcheux e a teoria do discurso nos anos 60. Expressáo (Santa Maria), v. 1, p. 186-192, 2006.

RASIA, G. L. S. Os discursos sobre língua e o ensino no Brasil da $\mathbf{1}^{\mathbf{a}}$ e da $2^{a}$ República: o duplo lugar da determinação e da contradiçáo. 2004. 297 f. Tese (Doutorado em Letras). Universidade Federal do Rio Grande do Sul, Porto Alegre, 2004.

ROCHA LIMA, C; H. Gramática Normativa da Língua Portuguesa. 15. ed. Rio de Janeiro: José Olympio, 1972. 
SAUSSURE, Ferdinand de. Escritos de Linguística Geral. Organizado e editado por Simon Bouquet e Rudolfo Engler. Tradução Carlos Augusto Leuba Salum e Ana Lúcia Franco. São Paulo: Cultrix, 2002.

SURDI, M. I. Gramática Normativa: movimentos e funcionamentos do "diferente" no "mesmo". Dissertação (Mestrado em Letras). Programa de Pós-graduação em Letras. Universidade Federal de Santa Maria. Santa Maria, RS, 2010.

SURDI DA LUZ, M. N. Linguística e ensino: discurso de entremeio na formação de professores de língua portuguesa. Tese (Doutorado em Letras). Programa de Pós-graduação em Letras. Universidade Federal de Santa Maria. Santa Maria, RS, 2010.

Marcia Ione Surdi - misurdi@uniochapeco.edu.br Mary Neiva Surdi da Luz - neivadaluz@gmail.com

Artigo recebido em 12 de dezembro de 2014 e aceito em 16 de janeiro de 2015. 